\title{
Membrane bioreactor biomass characteristics and microbial yield at very low mean cell residence time
}

\author{
WF Harper (Jr)*, M Bernhardt and C Newfield \\ Auburn University, Environmental Engineering Department, 238 Harbert Engineering Center, Auburn, AL, USA 36849-5337
}

\begin{abstract}
Membrane bioreactors (MBRs) are an exciting and evolving technology that replaces gravity sedimentation with micro- or ultra-filtration. MBRs are typically operated at low mean cell residence times (MCRTs), but there are cases when operating at very low MCRT may be more beneficial. In this study, a laboratory-scale MBR and SBR were operated in parallel and at very low MCRTs ( $3 \mathrm{~d}, 2 \mathrm{~d}, 1 \mathrm{~d}$ and $0.5 \mathrm{~d}$ ) to assess the relative bioreactor performance, biomass characteristics, and microbial yield. This study confirmed that the MBR maintains higher solids levels and better overall effluent quality than conventional bioreactors at all MCRTs tested. The MBR biomass particles were approximately $10 \mu \mathrm{m}$, which was significantly smaller than those of the SBR under all operating conditions tested. The MBR sludge typically did not dewater as well as that of the SBR. As the MCRT was decreased, the SBR particle size became smaller and the dewaterability improved, which supports the notion that smaller particles dewater better because there is less bound water present. The MBR sludge was more hydrophobic, which should result in more sorption of organic micro-pollutants like pharmaceutical compounds. These experiments also showed that the MBR biomass true yield was higher than that of the SBR. This study expands the MBR dataset available for very low MCRT operation.
\end{abstract}

Keywords: membrane bioreactors; microbial yield; biomass characteristics

\section{Introduction}

Membrane bioreactors (MBRs) are an evolving wastewater treatment technology that uses a suspended growth bioreactor, like in conventional activated sludge, but replaces gravity sedimentation with micro- or ultra-filtration. The membrane filtration unit allows for nearly complete retention of particles, high MLSS concentrations and production of an effluent very low in total suspended solids (TSS) and turbidity. It eliminates the need for secondary clarification, which in turn allows the overall treatment process to be sited on a much smaller footprint. MBRs are now becoming more common due to these operating advantages.

MBRs tend to operate at long mean cell residence times (MCRTs) in order to maintain high MLSS concentrations and to support nitrification, but under these operating conditions the aeration requirements pose a serious process limitation because of the high oxygen demand and the need to scour the membrane to slow the rate of fouling. Another concern at long MCRT is the production of soluble microbial products which can cause membrane fouling and produce too much colour (Rittmann and McCarty, 2001). MBR operation at low MCRT may be a prudent option for facilities that wish to avoid these disadvantages, reduce energy requirements, or reuse waste biosolids for the production of renewable resources like methane gas or biodegradable biopolymers (i.e. polyhydroxyalkanoates).

Currently there are very few data available concerning MBR operation at low MCRT. To date, Ng and Hermanowicz (2005) have provided the only available study of MBR operation at low MCRT. They operated a laboratory-scale MBR and

\footnotetext{
* To whom all correspondence should be addressed.

政 (334) 844-6260; fax: (334) 844-6290;

e-mail: wharper@eng.auburn.edu

Received 22 June 2005; accepted in revised form 12 January 2006
}

conventional activated sludge system at MCRTs ranging from $5 \mathrm{~d}$ to $0.25 \mathrm{~d}$. They found that the MBR achieved superior removal of COD and lower levels of effluent TSS. They also found that the MBR biomass was composed of fairly small, weak, and uniformly sized particles with a high fraction of nonflocculating organisms and very little exocellular polymer. The biomass in the conventional activated sludge system was composed of relatively large flocs when the MCRTs was greater than $2.5 \mathrm{~d}$, but the floc was much smaller and weaker when the MCRT was shorter. They also found that the MBR microbial yield was greater than that of the conventional activated sludge system, in spite of the fact that both systems were operated under the same conditions (i.e. same MCRTs, electron donors and acceptors). $\mathrm{Ng}$ and Hermanowicz (2005) presented important data regarding MBR operation at low MCRT; however, critical information is still needed. In addition to confirming their overall conclusions related to process performance and microbial yield, there is a need for more information about the MBR sludge characteristics (e.g. particle size, hydrophobicity and dewaterability) at low MCRT conditions.

Previous work shows that particle size affects dewaterability. There is a common notion that dewaterability is negatively affected by small particle size because the high specific surface area increases the frictional resistance to the withdrawal of water. Karr and Keinath (1978) corroborated this idea by showing that too many solids in the 1 to $100 \mu \mathrm{m}$ range were detrimental to dewaterability. However, more recently, Jin and Lant (2004) showed that floc size correlates negatively with dewaterability for floc sizes between approx. 50 and $200 \mu \mathrm{m}$, and they postulated that larger particles contained more bound water and were therefore more difficult to dewater. It is possible to reconcile these two studies by postulating that particles smaller than $50 \mu \mathrm{m}$ negatively affect dewaterability; this issue directly affects MBR operation, because MBRs are known to operate with particles smaller than $50 \mu \mathrm{m}$ (Yi and Harper, 2005; 


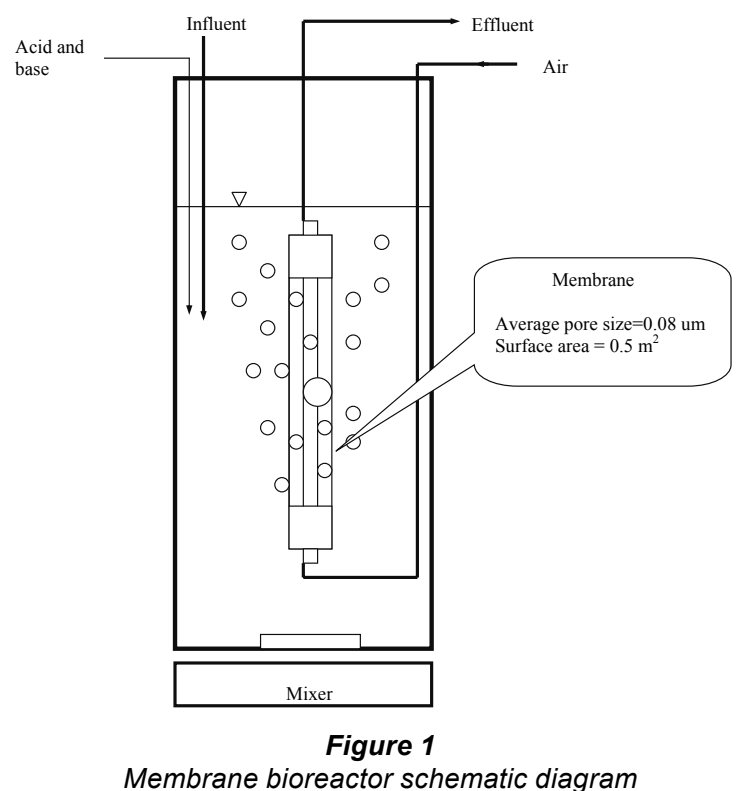

Henriques et al. (2005); Wisniewski et al. (2000); Wisniewski and Grasmick (1998)).

Hydrophobicity is another key sludge characteristic because it is a measure of how readily biomass particles reject water (Guellil et al., 1998). In general, lower sludge hydrophobicity is expected at low MCRT because less exocellular polymer is present (Liao et al. (2001)). In MBR systems, sludge hydrophobicity has attracted attention because of evidence that MBR sludges better sorb organic micro-pollutants than conventional bioreactors. Yi and Harper (2005) operated an MBR and SBR in laboratory-scale experiments at an MCRT of $20 \mathrm{~d}$, and they found that the MBR sludge was more hydrophobic than the conventional bioreactor sludge. The reason for the enhanced hydrophobicity was not clear, but they postulated that the high MBR hydrophobicity could be due to the exposed microbial surface area associated with small particles. There is now a need to determine whether MBRs maintain more hydrophobic particles than conventional bioreactors in the low MCRT range where particles are generally less hydrophobic.

The objectives of the current study are to expand the set of MBR operating data available at very low MCRT, including needed information about particle characteristics (i.e. size, dewaterability, hydrophobicity) and microbial yield. These data will be analyzed relative to a comparably operated SBR.

\section{Materials and methods}

Two laboratory-scale bioreactor systems were operated, including a membrane bioreactor and an aerobic sequencing batch reactor. Both bioreactors were originally seeded with mixed liquor from the City of Auburn Wastewater Treatment Facility. The experimental strategy was to operate both bioreactors at MCRTs of 3, 2, 1, $0.5 \mathrm{~d}$. At each MCRT, the bioreactors were operated for a total of 4 weeks.

\section{Bioreactor configuration and operation}

The membrane bioreactor had a working volume of $60 \ell$ and was equipped with one, vertically-mounted membrane module (pore size $(0.08 \mu \mathrm{m})$, physical size $(558 \mathrm{~mm}$ total length), surface area $\left(0.5 \mathrm{~m}^{2}\right)$, courtesy of Vivendi/US Filter), completely submerged in a Plexiglass vessel (Fig. 1). The module was 558 $\mathrm{mm}$ in length, and had a $76.2 \mathrm{~mm}$ diameter. The height of the vessel was $914 \mathrm{~mm}$, with $152 \mathrm{~mm}$ of freeboard, and a $762 \mathrm{~mm}$ water depth. The module was placed to allow a $102 \mathrm{~mm}$ clearance both from the vessel bottom and the water surface. The module was mounted in the middle of the vessel, and held in place by a Plexiglas U-shaped support apparatus. The physical dimensions of the Plexiglas vessel were driven by the dimensions of the membrane module. The height of the Plexiglas vessel was $914 \mathrm{~mm}$ in order to allow for $152 \mathrm{~mm}$ of freeboard and to allow $102 \mathrm{~mm}$ of clearance between the water surface and the vessel bottom. The cross section was square-shaped with a width of $279 \mathrm{~mm}$ to provide $229 \mathrm{~mm}$ of clearance between the module and the side wall. This latter dimension was recommended by the vendor to avoid sidewall effects. The influent flow $(30 \mathrm{l} / \mathrm{d})$ was selected to yield a flux of $40 \mathrm{m \ell} / \mathrm{min} \cdot \mathrm{m}^{2}$; this flux was targeted to minimise the membrane fouling rate as recommended by the vendor. This combination of reactor size and influent flow resulted in a HRT of $2 \mathrm{~d}$. The MCRT was varied according to the aforementioned experimental strategy. To maintain the desired MCRT, sludge wasting was carried out by wasting directly from the mixed liquor. To achieve very low MCRTs, (i.e. MCRT < HRT), the waste activated sludge was centrifuged, and the required volume of supernatant was returned to the bioreactor. The amount of waste activated sludge depended on the concentration of the MLVSS and the effluent VSS.

The membrane was operated with a target trans-membrane pressure differential of $27.6 \mathrm{kPa}$.The membranes were cleaned every $3 \mathrm{~d}$. To clean the membranes, each membrane was removed and placed in a separate vessel. Sodium hypochlorite $(200 \mathrm{mg} / \ell$ as free chlorine) was pumped through the membranes for $5 \mathrm{~min}$, and then the membranes were allowed to soak for $15 \mathrm{~min}$. The membranes were then backwashed with chlorinated permeate for $2 \mathrm{~min}$, after which they were soaked for another $15 \mathrm{~min}$. The membranes were then ready for normal operation in the MBR.

Masterflex pumps were used in order to control the influent and effluent flow. The airflow rate was maintained at $10 \mathrm{l} / \mathrm{min}$ to sustain a DO concentration of $2 \mathrm{mg} / \ell$ and to provide mixing. The pressure drop across the membrane was monitored continuously using a pressure gage. The $\mathrm{pH}$ was controlled with an auto-pH meter (alpha pH 200 1/8-DIN pH/ORP Controller, EUTECH Instruments Pte Ltd, Singapore) and $\mathrm{pH}$ electrode (Thermo Orion Glass pH electrode, Orion Research, INC. Beverly, MA). The $\mathrm{pH}$ of each reactor was maintained in the range of 6.8 to 7.3 by the addition of $0.1 \mathrm{M}$ HCL solution or $0.1 \mathrm{M} \mathrm{NaOH}$ solution. The volumes of acid and base were monitored daily and the addition of new solution to the storage vials was recorded. The temperature was ambient (approx. $24^{\circ} \mathrm{C}$ ).

The SBR had a working volume of $4 \ell$, and operated on a continuous $6 \mathrm{~h}$ cycle with an HRT of $2 \mathrm{~d}$, and the MCRT was varied according to the aforementioned experimental strategy. The $6 \mathrm{~h}$ cycle consisted of the following phases: nutrient feed and deionised water addition ( $3 \mathrm{~min})$, aerobic reaction $(280 \mathrm{~min})$, settling (30 min), effluent withdrawal (12 $\mathrm{min})$, and idle (35 min). The timing of the operation for the influent and effluent pumps, air and $\mathrm{N}_{2}$ flow, mixing and $\mathrm{pH}$ electrode activity, was controlled by a programmable logic controller (Model XT, Chrontrol Corporation, San Diego, CA). The $\mathrm{N}_{2}$ sparging occurred only during the 3 min fill phase just prior to the aerobic reaction phase as a precaution, preventing premature oxidation of the influent organic material. MCRT was maintained by manually wasting a portion of the mixed reactor contents once per day. The wasting was performed during the same cycle each day after reactor TSS samples had been taken and before the start of the settling phase. 
The $\mathrm{pH}$ was controlled with an auto-pH meter (WDP Series Dual Input pH/ORP Controller, Walchem Corporation, Holliston, MA) and pH electrode (WEL-PHF-NN electrode, Walchem Corporation, Holliston, MA) with a protective housing (Model 102606, Walchem Corporation, Holliston, MA). The $\mathrm{pH}$ of each reactor was maintained in the range of 6.8 to 7.3 by the addition of $0.1 \mathrm{M}$ HCL solution or $0.1 \mathrm{M} \mathrm{NaOH}$ solution. The volumes of acid and base were monitored daily and the addition of new solution to the storage vials was recorded. There was no $\mathrm{pH}$ control during the settling or effluent withdrawal phases. The temperature was ambient (approx. $24^{\circ} \mathrm{C}$ ).

\section{Synthetic wastewater}

The synthetic wastewater was used in order to provide a consistent influent feed composition, and it was the same for the MBR and the SBR. The organic substrate (acetic acid) and inorganic nutrients were added in separate feed streams. The composition of the synthetic feed was (as $\mathrm{mg} \mathrm{COD} / \ell$ total influent concentration: acetate (480), casamino acids (20). The inorganic salts content was (as $\mathrm{mg} / \mathrm{l}$ total influent concentration): $\mathrm{KCl}$ (210), $\mathrm{MgCl}_{2}-6 \mathrm{H}_{2} 0$ (394), $\mathrm{MgSO}_{4}-7 \mathrm{H}_{2} \mathrm{O}$ (26), $\mathrm{CaCl}_{2}(80), \mathrm{H}_{3} \mathrm{BO}_{3}$ $\left(0.11, \mathrm{ZnSO}_{4}-7 \mathrm{H}_{2} 0(0.0 .50), \mathrm{KI}(0.027), \mathrm{CuSO}_{4}-5 \mathrm{H}_{2} 0(0.11)\right.$, $\mathrm{Co}\left(\mathrm{NO}_{3}\right) 2-6 \mathrm{H}_{2} \mathrm{O}$ (0.135), $\mathrm{NaMoO}_{4}-2 \mathrm{H}_{2} \mathrm{O}(0.056), \mathrm{MnSO}_{4}-\mathrm{H}_{2} 0$ (0.62), and $\mathrm{FeSO}_{4}-7 \mathrm{H}_{2} 0(0.55)$. The influent TOC concentration of the influent wastewater was $187 \mathrm{mg} / \ell$. The influent $\mathrm{P}$ concentration was supplied as $\mathrm{NaH}_{2} \mathrm{PO}_{4}-2 \mathrm{H}_{2} \mathrm{O}$ and was always $8.0 \mathrm{mg}$ $\mathrm{P} / \ell$. The influent $\mathrm{N}$ was supplied as $\mathrm{NH}_{4} \mathrm{Cl}$ and was always 54.3 $\mathrm{mg} \mathrm{N} / \ell$. It is likely that this synthetic wastewater is more biodegradable than real wastewater.

\section{Analytical methods}

Total organic carbon was measured according to Standard Methods (1992) was determined using a UV-persulphate TOC analyzer (Phoenix 8000, Tekmar-Dohrmann, Cincinnati, OH, USA). Total suspended solids (TSS) and volatile suspended solids (VSS) were analyzed according to Standard Methods (1992). Settled volumes for bioreactor samples were determined after a 30 min settling test in a $1 \ell$ cylinder (Standard Methods, 1992). Dewaterability was quantified using capillary suction time (CST), as measured using a filterability apparatus (Triton Electronics, Model 200, Essex, UK) and standard chromatography paper (Triton Electronics Ltd., 70x90 mm). The waste activated sludge used for measuring dewaterability test was first thickened by centrifuging a $250 \mathrm{~m} \ell$ sample for $1 \mathrm{~min}$ at $100 \mathrm{xg}$. Particle size distribution was determined on $15 \mathrm{~m} \ell$ samples from the MBR and SBR utilising a Horiba LA-920 laser-scattering particle size distribution analyzer (Delta Analytical Instruments, North Huntington, PA). The microbial adhesion to hydrocarbon test (MATH) test can be used to measure sludge hydrophobicity (Guellil et al., 1998), and was conducted as follows: Cells were centrifuged at $2000 \mathrm{xg}$ for $10 \mathrm{~min}$ and washed and re-suspended three times in phosphate urea magnesium sulphate buffer (16.9 $\mathrm{g} \mathrm{K}_{2} \mathrm{HPO}_{4}$, $7.26 \mathrm{~g} \mathrm{KH}_{2} \mathrm{PO}_{4}, 1.8 \mathrm{~g}$ urea, $0.02 \mathrm{~g} \mathrm{MgSO}_{4}-7 \mathrm{H}_{2} \mathrm{O}$, pH 7). Cell density was adjusted to an optical density at $600 \mathrm{~nm}$ (OD 600) of 0.4-0.6. The cell suspension $(4 \mathrm{ml})$ was transferred to test tubes and $0.8 \mathrm{~m} \ell \mathrm{n}$-hexadecane was added. After the mix was homogenised for $2 \mathrm{~min}$ at full speed using a Vortex mixer, the hydrocarbon phase was allowed to separate completely (15 min) and the aqueous phase was removed to determine the OD600. Hydrophobicity was calculated using the following equation:

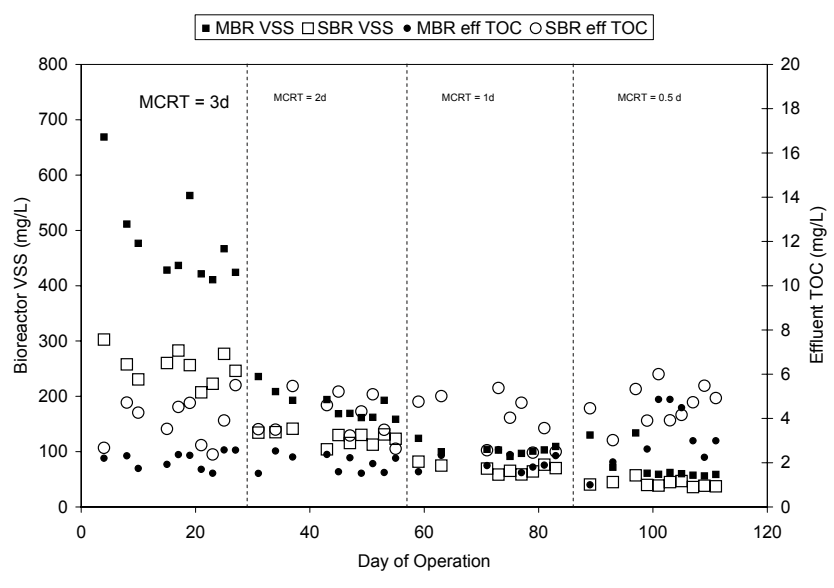

Figure 2

Bioreactor VSS and TOC removal

percentage of adhesion $=100 \times$ [OD600 (initial bacterial suspension) - OD600 (aqueous phase)]/OD600 (initial suspension)

It is important to note that the two bioreactors were operated in different modes (i.e. the MBR was operated in continuous mode and the conventional reactor was operated in batch mode). The MBR was operated in continuous mode because this mode allows for operation at the target permeate flux. This is in contrast to the batch mode, which would require operation at a relatively high permeate flux during the effluent withdrawal stage, and would therefore result in very fast membrane fouling and elevated effluent TSS levels. The continuous mode is common for MBRs. The conventional bioreactor was, in this case, operated in batch mode because of the nature of the experiments being conducted. At low MCRT, activated sludge is known to settle poorly (Metcalf and Eddy, 2003). However, bioreactors operated in the batch mode are known to settle better than bioreactors that are operated in continuous mode (Metcalf and Eddy, 2003). Sludge settling was an important problem in the previous similar study conducted by $\mathrm{Ng}$ and Hermanowicz (2005), who operated a continuous conventional system at very low MCRT. They experienced very poor sludge settling, so that they had to centrifuge the effluent and return the solids to the reactor for MCRT control. Therefore, the conventional reactor was operated in batch mode in an attempt to produce sludge that settled well-enough to control the solids inventory at low MCRT.

\section{Results and discussion}

\section{Process performance}

MBRs are known to maintain higher solids levels and better overall effluent quality than conventional bioreactors (Metcalf and Eddy, 2003). The results obtained during the current study were consistent with this previous experience (Fig. 2). As expected, the MBR VSS levels were higher than those for the SBR, and the VSS levels for both bioreactors decreased as the MCRT was lowered. At an MCRT of $3 \mathrm{~d}$, the MBR maintained VSS levels of approximately $450 \mathrm{mg} / \ell$ compared to approximately $250 \mathrm{mg} / \ell$ for the SBR. The VSS levels for both bioreactors dropped as the MCRT was decreased. The MBR VSS was $170 \mathrm{mg} / \ell$ at an MCRT of $2 \mathrm{~d}$, approximately $100 \mathrm{mg} / \ell$ at $1 \mathrm{~d}$, and approximately $65 \mathrm{mg} / \ell$ at an MCRT of $0.5 \mathrm{~d}$. The MBR VSS was $170 \mathrm{mg} / \ell$ at an MCRT of $2 \mathrm{~d}$, approximately $100 \mathrm{mg} / \ell$ at 


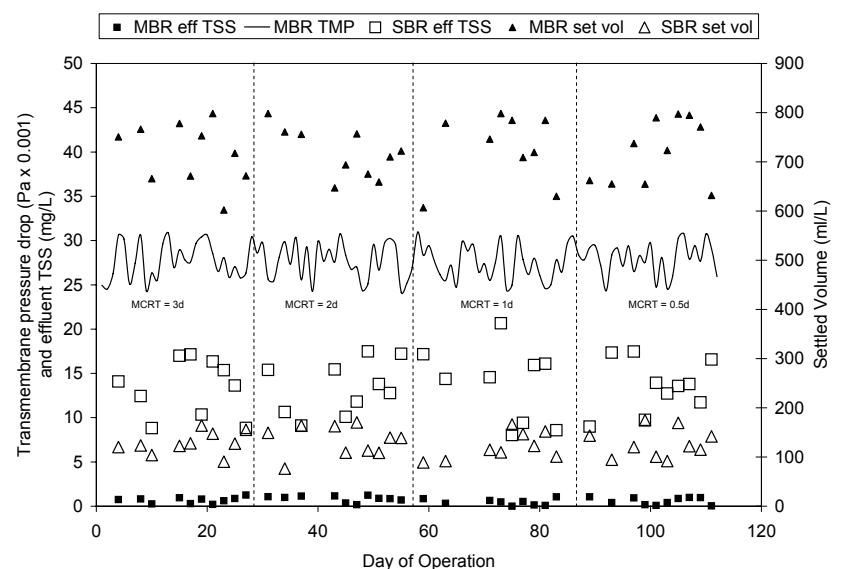

Figure 3

Bioreactor effluent suspended solids levels, TMP and Settled Volume

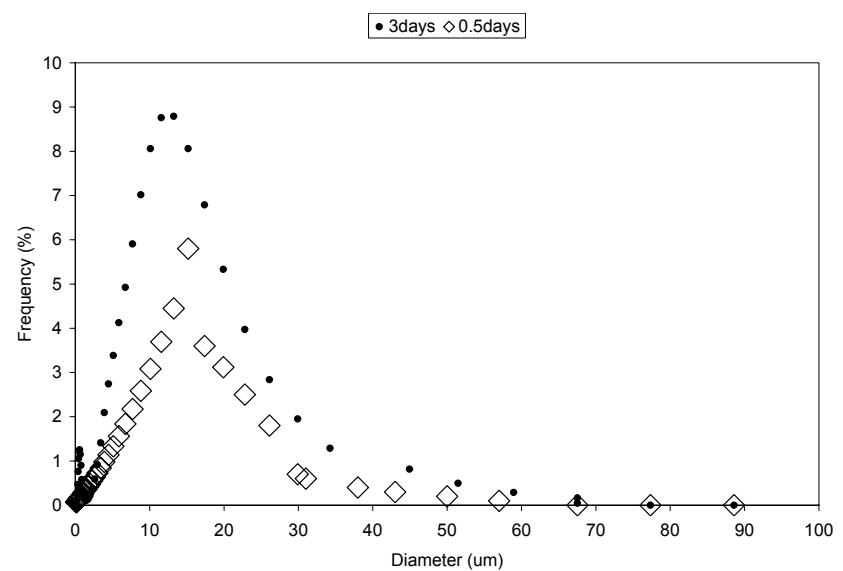

Figure 4

Typical MBR particle size distributions

$1 \mathrm{~d}$, and approximately $65 \mathrm{mg} / \ell$ at an MCRT of $0.5 \mathrm{~d}$. The MBR effluent TOC was generally lower than that of the SBR, likely because it retains more active biomass and thus removes soluble compounds more efficiently.

In addition, as expected, the MBR effluent TSS was lower than that of the SBR (Fig. 3). The MBR effluent TSS was $<2$ $\mathrm{mg} / \ell$ under all operating conditions, compared to the SBR effluent TSS which ranged from 8 to $21 \mathrm{mg} / \ell$ TSS. Because the MBR used ultra-filtration for solids removal, the effluent TSS levels were not related to the quality of sludge settling. The MBR settled volumes were between 600 to $800 \mathrm{~m} \ell / \ell$ and were significantly higher than those of the SBR, which were from 100 to $200 \mathrm{~m} \ell / \ell$. During the operation of the MBR the trans-membrane pressure drop was fairly constant (approx. $27000 \mathrm{~Pa}$ ), which was probably due to the frequency of membrane cleaning. Taken together, the results from Figs. 2 and 3 show that the MBR produced an effluent stream with higher overall quality, and it did so while maintaining higher bioreactor solids levels. These benefits have been shown at higher MCRTs, and these results assist in showing that these benefits are also present at very low MCRTs.

\section{Biomass characteristics}

MBR and SBR particle size distributions are shown in Figs. 4 and 5 respectively. PSDs were determined for both bioreactors

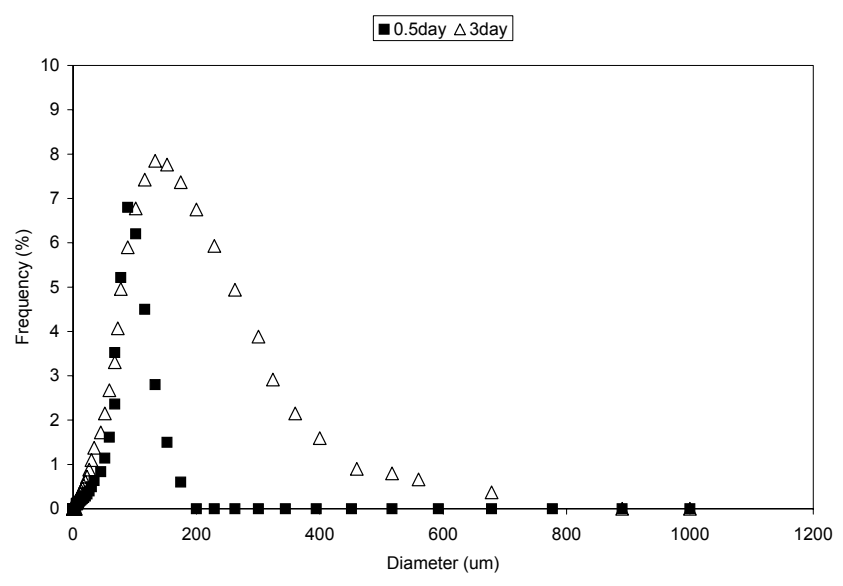

Figure 5

Typical SBR particle size distributions

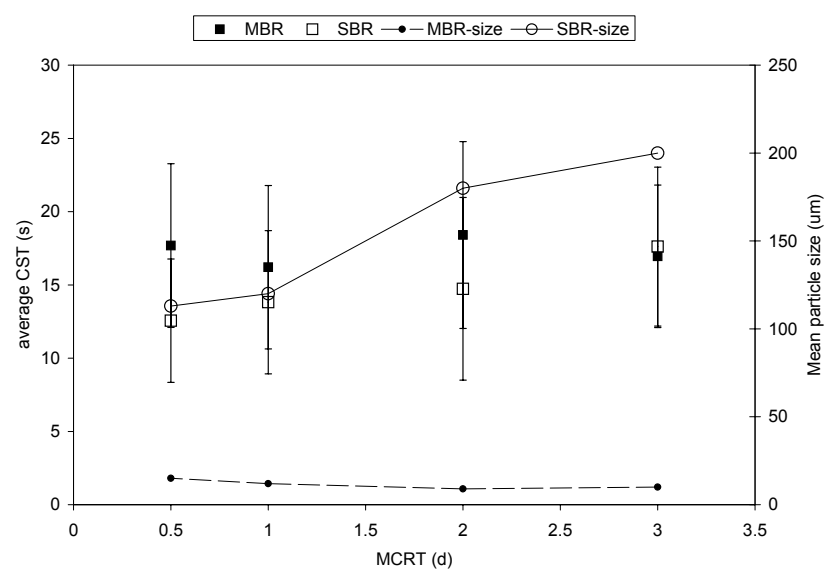

Figure 6

Capillary suction time

at all MCRTs, but for clarity, the figures only show the PSDs associated with MCRTs of 3 and $0.5 \mathrm{~d}$. The average MBR particle size was approx $10 \mu \mathrm{m}$ for all MCRTs tested (Fig. 4). The range of MBR particle sizes was very narrow, because $99 \%$ of the MBR particles were less than $50 \mu \mathrm{m}$ at each MCRT. The MBR sludge was generally dispersed at all MCRTs tested, with very small, weak pin-point floc. The SBR floc was noticeably larger and denser at MCRTs of 3 and $2 \mathrm{~d}$, but the floc was more dispersed and the particles smaller at MCRTs of 1 and $0.5 \mathrm{~d}$ (Fig. 4). The average SBR particle size decreased noticeably as MCRT was lowered; it was $120 \mu \mathrm{m}$ at $3 \mathrm{~d}$ and $2 \mathrm{~d}, 100 \mu \mathrm{m}$ at MCRT of $1 \mathrm{~d}$, and $90 \mu \mathrm{m}$ at MCRT of $0.5 \mathrm{~d}$. The SBR particle size range decreased as the MCRT was lowered. When the MCRT was $3 \mathrm{~d}, 98 \%$ of the particles were in the size range of between 50 and $500 \mu \mathrm{m}$, but when the MCRT was $0.5 \mathrm{~d}$, the particles were in the size range of between 50 and $180 \mu \mathrm{m}$.

Both sludges were viewed microscopically, and very few filaments were observed in either of the systems. No higher life forms like protozoa or rotifers were found during the experiments.

The MBR CST values were generally higher than those of the SBR biomass (Fig. 6). The MBR CST values were between 10 and $28 \mathrm{~s}$, and the average value was $18 \mathrm{~s}$. The SBR CST values were from 6 to $23 \mathrm{~s}$, and the average value was $14 \mathrm{~s}$. These results show that the MBR sludge typically dewatered more poorly and may therefore require more polymer addition for effective 


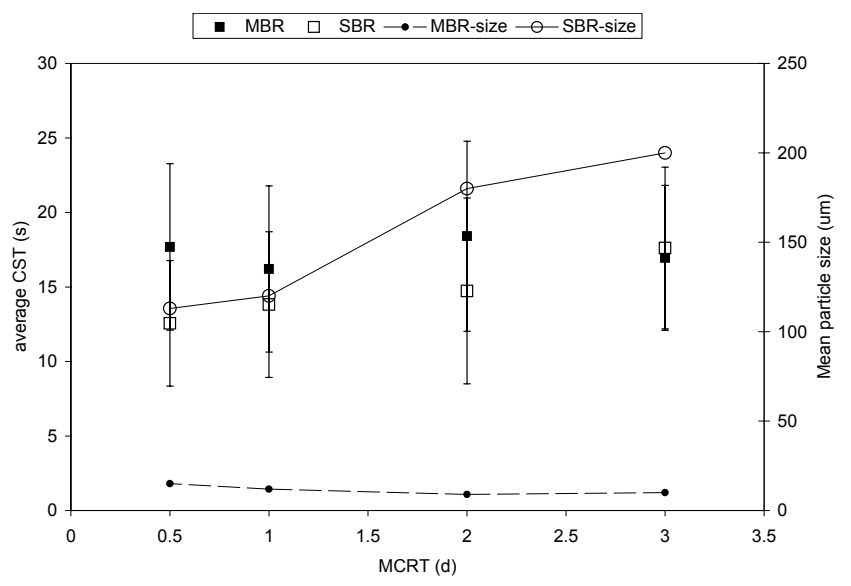

Figure 7

Average CST and MCRT

sludge treatment. These CST results are useful for comparing the relative dewaterability of the MBR and SBR sludges; however, the CST values reported here will not directly translate to CST values that can be expected in practice because the TSS concentrations will be much greater in full-scale systems.

As discussed previously, there likely is a connection between CST values and particle size. However, because of the wide range of measured values for both bioreactors, the precise nature of the cause-and-effect relationship in this study is not clear. Figure 7 shows the relationship between the average CST, particle size, and the MCRT. The difference between the average CST of the MBR and SBR for each MCRT was not statistically significant (the error bars shown are associated with CST measurements). The MBR particle size and average CST were relatively constant throughout the experiment, and it was therefore not possible to assess the affect of particle size on CST for particles over a range of sizes smaller than $50 \mu \mathrm{m}$. The SBR particle size dropped from approx. $200 \mu \mathrm{m}$ to $113 \mu \mathrm{m}$ as the MCRT was lowered and the average SBR CST decreased as MCRT was lowered. This SBR particle size regime is within the range studied by Jin and Lant (2004), and this result supports the notion that particles in this size range dewater better as the size decreases.

Sludge hydrophobicity is a key parameter that strongly influences the sorption of organic compounds. In the current study, the MBR sludge was more hydrophobic than the SBR biomass (Fig. 8 ). The MBR hydrophobicity averaged $38 \%$, and was between 20 and $53 \%$, but there no discernable trends were observed as the MCRT was reduced. The SBR hydrophobicity averaged 25\% and varied between 17 and $32 \%$. Because the MBR sludge was more hydrophobic on average, it should capture (via sorption) hydrophobic pollutants better than the SBR during low MCRT operation.

\section{Microbial yield}

In biological systems, the net specific growth rate $(\mu)$ is related to the food-to-micro-organism $(q)$ ratio as follows:

$$
\mu=\mathrm{Yq}-\mathrm{b}
$$

Thus the true microbial yield can be determined by plotting $\mu$ vand $q ;. \mu$ was calculated by taking the inverse of the MCRT. The following equation was used to determine $q$ :

$$
q=Q\left(C_{\text {in }}-C_{\text {out }}\right) /(X V)
$$

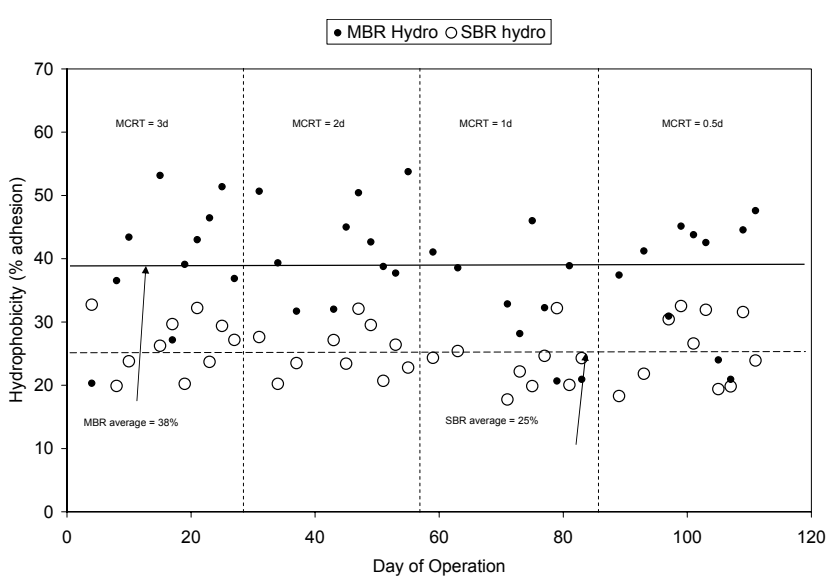

Figure 8

Hydrophobicity

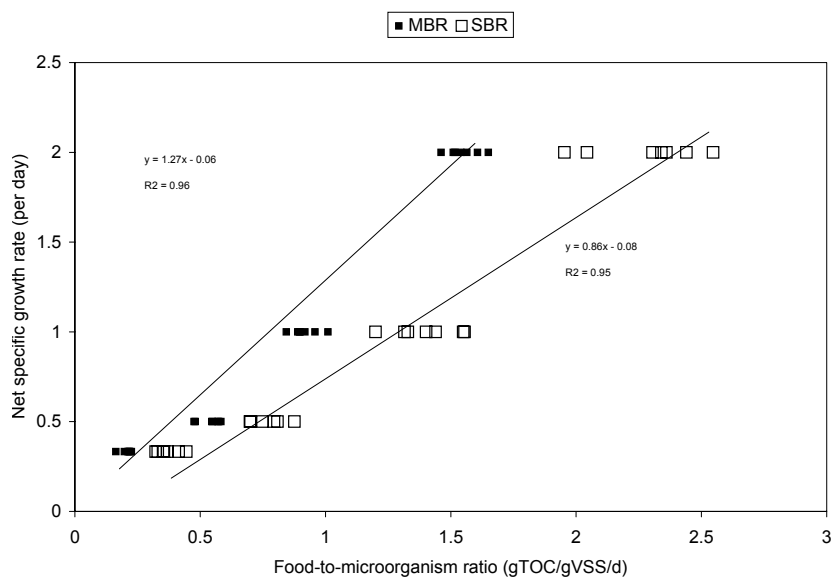

Figure 9

Microbial yield determination

where:

$\mathrm{Q}$ is the daily flow rate

$\mathrm{C}_{\text {in }}$ and $\mathrm{C}_{\text {out }}$ are the influent and effluent TOC concentrations respectively

$\mathrm{X}$ is the biomass VSS concentration in the bioreactor

$\mathrm{V}$ is the volume of the bioreactor

The effluent TOC and biomass VSS concentration were measured (as shown in Fig. 2). The influent TOC concentration, wastewater flow, and bioreactor volume were measured and described in the materials and methods section.

For example, on the $19^{\text {th }}$ day of operation, the $q$ for the MBR was calculated using the following values: $\mathrm{X}=563 \mathrm{mg} \mathrm{VSS} / \ell$, $\mathrm{Q}=30 \ell / \mathrm{d}, \mathrm{V}=60 \ell, \mathrm{C}_{\text {out }}=2.3 \mathrm{mgTOC} / \ell$, and $\mathrm{C}_{\text {in }}=187 \mathrm{mg}$ $\mathrm{TOC} / \ell$. Therefore, $q$ is:

$$
\begin{aligned}
& q=30 \ell / \mathrm{d}(187 \mathrm{mg} / \ell-2.3 \mathrm{mg} / \ell) /\left(563 \mathrm{mg} / \ell^{*} 60 \ell\right) \\
& =0.16 \mathrm{mg} \mathrm{TOC} / \mathrm{mgVSS} / \mathrm{d}
\end{aligned}
$$

Figure 9 shows that the true microbial yield for the MBR was $1.27 \mathrm{gVSS} / \mathrm{gTOC}$ and $0.86 \mathrm{gVSS} / \mathrm{gTOC}$ for the SBR. On a COD basis, these yields are $0.45 \mathrm{gVSS} / \mathrm{gCOD}$ and $0.3 \mathrm{gVSS} / \mathrm{gCOD}$ respectively. These results agree with those of $\mathrm{Ng}$ and Hermanowicz (2005), who showed that the MBR and conventional bioreactor true yields were $0.42 \mathrm{gVSS} / \mathrm{gCOD}$ and $0.35 \mathrm{gVSS} / \mathrm{gCOD}$ respectively. These results, as well as those of $\mathrm{Ng}$ and Hermano- 
wicz (2005), show that the true microbial yield in the MBR is higher than that of an aerobic activated sludge process that uses gravity sedimentation.

The difference in true yields between the MBR and SBR can be explained by considering the bioenergetic basis for microbial yield prediction (McCarty, 1964; 1971). The process commences with a basic intracellular energy balance which results in the following:

$$
A=\frac{\frac{-\Delta \mathrm{Gp}}{\epsilon^{\mathrm{m}}}-\Delta \mathrm{Gc}}{\epsilon \Delta \mathrm{Gr}}
$$

where:

$E$ is the efficiency of energy transfer to or from the energy carrier (e.g., ATP)

$\Delta \mathrm{Gr}$ is the free energy released per electron equivalent of electron-donor substrate converted for energy (e.g. respiration)

$\Delta \mathrm{Gs}$ is the carrier (ATP) energy required to synthesise 1 electron equivalent of cells from whatever the carbon and nitrogen sources are

$\Delta \mathrm{G}_{\mathrm{C}}$ is the ATP energy required to form 1 mole of active cells (i.e. $1 / 20 \mathrm{C}_{5} \mathrm{H}_{7} \mathrm{O}_{2} \mathrm{~N}$ ) from pyruvate and ammonia. $\mathrm{A}$ is the electron equivalent of electron donor converted to energy per electron equivalent of cells synthesised, and it is directly related to $\mathrm{Y}$ :

$$
\mathrm{Y}=\frac{5.65}{8^{*}(1+\mathrm{A})}
$$

In principle, since the MBR and SBR were operated under the same operating conditions (i.e. same MCRT, electron donor and acceptor), the same values for $\Delta \mathrm{Gr}, \Delta \mathrm{Gs}$ and $\Delta \mathrm{G}_{\mathrm{C}}$ are used for predicting microbial yield. The only remaining term that could be different for the two systems is the efficiency of energy transfer. This value can vary from 0.2 to 0.8 in a given isolate, but values of between 0.4 and 0.7 are often used where bioreactors are concerned. The true yield of the MBR may be higher because of higher overall electron transfer efficiency, which means that higher $C$ values must be used when modelling MBR sludge production. To investigate this issue comprehensively, future experiments should include electron transfer efficiency measurements

\section{Conclusions}

This study confirmed that the MBR maintains higher solids levels and better overall effluent quality than conventional bioreactors at very low MCRT. The MBR biomass particles were smaller than those of the SBR but did not dewater as well on average. As the MCRT was decreased from $3 \mathrm{~d}$ to $0.5 \mathrm{~d}$, the MBR particle size and CST did not change significantly, but the SBR particle size became smaller and the dewaterability improved (i.e. CST decreased), supporting the notion that floc size correlates negatively with dewaterability in the 50 to $200 \mu \mathrm{m}$ size range. The MBR sludge was more hydrophobic, which should result in more sorption of organic micro-pollutants like pharmaceutical compounds. The MBR true yield was higher than that of the SBR; future experiments should focus on electron transfer efficiency as the underlying reason for this observation. This study expands the MBR dataset available for very low MCRT operation.

\section{Acknowledgements}

This research was supported in part by the Auburn University Environmental Institute and Auburn University undergraduate research program. The authors thank Taewoo Yi, Jinling Zhaung, Eric Brown, and the staff at the City of Auburn Wastewater Treatment Plant for their assistance.

\section{References}

GUELLIL A, BLOCK J and URBAIN V (1998) Adaptation of the microbial adhesion to hydrocarbon test (MATH) for measuring activated sludge hydrophobicity. Water Sci. Technol. 37 (4-5) 359-362.

HENRIQUES I, HOLBROOK RD, KELLY R and LOVE N (2005) The impact of floc size on respiration inhibition by soluble toxicants A comparative investigation. Water Res. 39 (12) 2559-2568.

JIN B and LANT P (2004) Flow regime, hydrodynamics, floc size distribution and sludge properties in activated sludge bubble column, air-lift and aerated stirred reactors. Chem. Eng. Sci. 59 (12) 2379 -2388 .

KARR P and KEINATH T (1978) Influence of particle size on sludge dewaterability. J. Water Pollut. Control Fed. 50 (7) 1911-1930.

LIAO B, ALLEN D, DROPPO I, LEPPARD G and LISS S (2001) Surface properties of sludge and their role in bioflocculation and settleability. Water Res. 35 (2) 339-350.

McCARTY PL (1964) Thermodynamics of biological synthesis and growth. Proc. 2nd Int. Water Pollut. Res. Conf. Tokyo, 1964. 169-199.

McCARTY PL (1971) Energetics and bacterial growth. Organic Compounds in Aquatic Environments. Marcel Dekker, Inc., New York. 495-512.

METCALF and EDDY (2003) Wastewater Engineering: Treatment and Reuse. McGraw-Hill Publishers, New York, NY. 1819 pp.

NG H and HERMANOWICZ S (2005) Membrane bioreactor operation and short solids retention times: Performance and biomass characteristics. Water Res. 39 (6) 981-992.

RITTMANN BE and McCARTY PL (2001) Environmental Biotechnology: Principles and Application. McGraw-Hill Publishers, New York, NY. 754 pp.

STANDARD METHODS (1992) Standard Methods for the Examination of Water and Wastewater $\left(18^{\text {th }}\right.$ edn.). American Public Health Association (APHA), American Water Works Association (AWWA), Water Pollution Control Federation (WPCF), Washington, DC. 1268 pp.

WISNIEWSKI C and GRASMICK A (1998) Floc size distribution in a membrane bioreactor and consequences for membrane fouling. Colloids Surfaces A Physicochem. Eng. Aspects 138 (2-3) 403-411.

WISNIEWSKI C, GRASMICK A and CRUZ, A (2000) Critical particle size in membrane bioreactors: Case of a denitrifying bacterial suspension. J. Membr. Sci. 178 (1-2) 141-150.

YI T and HARPER JR WF (2005) Mechanisms for removal of $17 \alpha$ ethinylestradiol in bioreactors. Proc. $78^{\text {th }}$ Annu. Water Environ. Fed. Tech. Exposition and Conf. Washington, DC, October 2005. 